EVIDENCE FOR METABOLIC ACTIVITY

OF AIRBORNE BACTERIA

2nd Quarter1y Report, 1973-74

NASA Contract W13450

Task No. 193-58-62-13-10

R. L. Dimmick, H. Wolochow, M. A. Chatigny, P. A. Straat, J. R. Schrot and G. V. Levin

(NASA-CR-139620) EVIDENCE FOR METABOLIC

N74-31552 ACTIVITY OF AIRBORNE BACTERIA QuarteIIY Report, $1973-1974$ (Naval Biomedical Research Lab., Dakland) 9 p HC $\$ 4.00$ CSCL $06 \mathrm{M} \mathrm{G} 3 / 04 \quad 47431$

\author{
NAVAL BIOMEDICAL RESEARCH LABORATORY \\ School of Public Health \\ Unţversity of California, Berkeley \\ Naval Supp1y Center \\ Oakland, California 94625
}


2nd Quarter1y Report, 1973-74

NASA Contract 'il 13450

Task No. 193-58-62-13-10

\section{EVIDENCE FOR METABOLIC ACTIVITY OF AIRBORNE BACTERIA}

R. L. Dimmick, H. Wolochow, M. A. Chatigny; P. A. Straat, J. R. Schrot and G. V. Levin

Aerosols of the bacterium Serratia marcescens, and of uniformly labelled ${ }^{14} \mathrm{C}$ glucose, were created simultaneous1y and mixed in tubing leading to an aerosol chamber. During a subsequent period of about $5 \mathrm{hrs},{ }^{14} \mathrm{CO}_{2}$ was produced unequivocally within the chamber, and "insoluble", labelled material within the suspended particles first increased, then decreased.

Current NASA planetary exploration projections include near flyby and probes of Jupiter, Saturn and possbily one or more of their satellites. Planetary quarantine ( $P Q)$ constraints developed in international agreements are applicable to such probes. Jupiter, in particular, has a deep gaseous atmosphere which includes methane, ammonia, and water, all in a dynamic convective mass in which there is a zone about $80 \mathrm{~km}$ thick where temperature and moisture conditions do not preclude the possibility of microbial growth (1). Examination of the probability of metabolism and growth $(\mathrm{Pg})$ of spacecraft-borne terrestrial microorganisms seeded into such clouds, and possibly maintained as aerosols, is an important factor in determining the degree of control required to meet our international commitments.

There are numerous experimental aerobiology publications citing presumptive evidence that airborne microorganisms support metabolic functions (2), but direct evidence has been lacking. The question is of importance not only in the approach to estimation of $\mathrm{Pg}$ in the Jovian atmosphere, but also is implicated in mechanisms of microbial survival in air (3), and is of fundamental, practical importance with respect to the airborne biota of our own planet (4).

Groups in our laboratory are studying the problems in three phases, 1 isted here generally in order of ease of proof. They are: (a) demonstration of the presence of some metabolic functions; (b) demonstration of transcription or of gene replication and (c) demonstration of growth (Propagation) of selected microorganisms in atmospheres providing organic matter potentially present or found in the Jovian atmosphere (5). The work described is the demonstration of the uptake of glucose and subsequent $\mathrm{CO}_{2}$ production by airborne Serratia marcescens (SM).

The strategy of the experiment was to mix two aerosols in a closed chamber--one aerosol of semi-starved bacteria and the other of $14 \mathrm{C}$ labeled glucose. If a "living" microbe collided with a glucose 
2nd Quarterly Report, 1973-74

NASA Contract W13450

Task No. 193-58-62-13-10

particle, the glucose could be transported into the cell and incorporated into metabolic pathways for production of labeled $\mathrm{CO}_{2}$. Labeled materials within microbes would increase by incorporation, then decrease through metabolism, and $\mathrm{CO}_{2}$ within the chamber would increase to some maximal leve1; this sequence is essentially what was observed.

Cultures of SM were grown in $0.01 \mathrm{M}$ phosphate buffer with added trace elements and ammonium ions, and with $0.5 \%$ glucose (as sole. carbon source) which was just sufficient to support growth of a population of about $5 \times 10^{9}$ cells $/ \mathrm{ml}$. Cultures were inoculated $16 \mathrm{hrs}$ prior to a given experiment. Cells were harvested by centrifugation within 10 minutes of the expected start time, and resuspended (ca $10^{10}$ ce1ls $/ \mathrm{m} 1$ ) in growth medium without glucose.

Uniformly-labeled ${ }^{14} \mathrm{C}-\mathrm{glucose}$ (Schwarz/Mann) solutions were adjusted with unlabeled glucose to concentrations of $0.5 \%$ and a specific. activities of $100 \mu \mathrm{Ci} / \mathrm{ml}$. Purity was established by thin-layer chromatography on silica ge1 using n-butanol: acetone: water $(30: 50: 20)$ as the solvent system. Acidification of the glucose solutions released less than $0.1 \%$ of the radioactivity as ${ }^{14} \mathrm{CO}_{2}$. Independent tests using the labeled release technique (6) established that in vitro mixing of these glucose solutions with SM resulted in the rapid evolution of ${ }^{14} \mathrm{CO}_{2}$.

Measurements of radioactivity were performed on a Beckman liquid scintillation counter equipped with a cesium external standard. The counting "cocktail" consisted of $0.25 \mathrm{~g}$ of 1,4-bis(2-(5-phenyloxazoly)) benzene (POPOP) and $2 \mathrm{~g}$ of 2,5-diphenyloxazole (PPO) added to $500 \mathrm{ml}$ of toluene and $500 \mathrm{~m} 1$ of methanol. Counting efficiency was established with ${ }^{14} \mathrm{C}$ benzoic acid (New England Nuclear) as prime standard.

A cell suspension and a glucose solution were atomized separately and simultaneously from two refluxing Wells atomizers having outputs of $0.2 \mathrm{ml} / \mathrm{min}$; efficiency of particulate emission was about $20 \%$ of total mass loss from the atomizer (7). The two atomizers were positioned in a tee-joint, opposed, and separated by about $4 \mathrm{~cm}$. The side outlet of the tee led to a copper tube $0.9 \mathrm{~cm}$ in diameter and $33 \mathrm{~cm}$ long which was connected to the input tubing $(0.3 \mathrm{~cm}$ in diameter, $44 \mathrm{~cm}$ long) of one or the other of a pair of rotating drums (1500 liters) ( 8 ). In independent experiments the coagulation efficiency during the 5-second sojourn of particles in the tubing was found to be about 15 percent; interaction of the two particulate species was not dependent upon coagulation within the drum.

Drums were located in a temperature-controlled chamber (21 C) and, prior to each run, were washed with clean air at $90-95 \%$ relative humidity until the humidity of the exit air was identical to the input air. Atomization then proceeded over a 5 -minute spray time, after 
2nd Quarterly Report, 1973-74

NASA Contract W13450

Tas!: No. 193-58-62-13-10

which each drum contained about $22 \mu \mathrm{Ci}(30,000 \mathrm{dpm} /$ liter $)$ glucose with (or without as appropriate) approximately 1010 ( $5 \times 10^{6} \mathrm{ce} 11 \mathrm{~s} / 1$ iter) viable bacterial cells suspended in the aerosol state. At various times after aerosolization, AGI-30 (9) impinger samples of 12.5 liters were collected into $20 \mathrm{ml}$ of phosphate buffer during one minute. These samples were analyzed for radioactive content and for viable bacterial count by serial, ten-fold dilution in gelatin-phosphate medium and plating on trypticase soy agar.

Gas samples were a1so collected for 30 -minute periods at various times throughout a run. The gas sampler system consisted of a $5 \mathrm{ml}$ immunological pipette with the tip immersed into $2 \mathrm{ml}$ of Hyamine hydroxide. The two were incorporated in a closed container such that air entering the container was removed via the pipette at a rate of about $60 \mathrm{ml} / \mathrm{min}$. In independent experiments, we found essentially $100 \%$ collection of $\mathrm{CO}_{2}$ at this flow rate. During collection, samples were first passed through a $0.1 \mathrm{\mu m}$ membrane filter to remove radioactive particles, and the volume of gas collected during the sampling period was measured by water displacement. Samples were then assayed for total radioactivity. Acidification of a Hyamine hydroxide aliquot with entrapment of subsequently evolved volatiles, e.g. $\mathrm{CO}_{2}$, on a filter pad moistened with barium hydroxide, established that the radioactivity present in the Hyamine hydroxide samples from the drums was $\mathrm{CO}_{2}$ (or possibly a weak volatile acid) and was devoid of glucose.

Results of a typical experiment in which separate preparations of ${ }^{14} \mathrm{C}-\mathrm{glucose}$ and $S M$ were mixed in the aerosol state are shown in Table 1. These results are compared. to a parallel experiment in which glucose alone was aerosolized into a second drum in the absence of SM. As shown, both glucose and the bacterial particles fell onto the walls of the drum with time, decreasing the concentration in the aerosol state. This fallout rate is a direct function of particle size and, for glucose, the disappearance of radioactive-labeled particles from the drum represents the actual fallout rate. For viable bacterial cells, however, the decrease in concentration within the drum represents both fallout and the loss of cell viability. It should be noticed that the fallout rate of radioactive glucose is considerably larger in the presence of SM than in the absence of bacterial cells and that the humidity was the same in both drums. This indicates that coagulation had occurred between glucose and SM forming larger particles than in the absence of SM. As shown, in the drum containing both glucose and $\mathrm{SM}$, the amount of ${ }^{14} \mathrm{CO}_{2}$ present gradually increased until a plateau was reached after about hours. At the plateau, the total amount of ${ }^{14} \mathrm{CO}_{2}$ represents approximately $7 \%$ of the original amount of radioactivity added to the drum. We do not understand the unusual, delayed disappearance of ${ }^{14} \mathrm{CO}_{2}$ in this one test (compare Table 3). Omission of SM from the drum resulted in production of less than $15 \%$ of the carbon dioxide accumulated in the presence of SM during the entire run. This indicates that most of the $\mathrm{CO}_{2}$ observed in the presence of both SM and glucose is metabolic in origin and not a result 
2nd Quarterly Report, 1973-74

NASA Contract W13450

Task No. 193-58-62-13-10

of some nonbiological interaction of glucose with residual material possibly present on the walls of the drums. As for ${ }^{14} \mathrm{CO}_{2}$ released in the absence of $S M$, separate experiments have shown that, despite scrupulous cleaning procedures between sequential experiments, some residual radioactivity remained on the walls of the drum at the start of the next experiment. Trace amounts were observed to be released very slowly as $\mathrm{CO}_{2}$ under the experimental conditions. Sometimes, after extended intervals, $\mathrm{CO}_{2}$ was comparable in magnitude to that seen in Table 1 in the absence of SM.

The results shown in Table 1 do not allow a clear distinction to be made between whether the source of $\mathrm{CO}_{2}$ production is from the aerosol state or is a result of fallout and subsequent metabolism on the wall. Indeed, the possibility of metabolism on the walls is suggested in Table 1 because $\mathrm{CO}_{2}$ increased as the concentration of airborne bacterial cells and glucose decreased by fallout; although $99 \%$ of the bacterial cells fell to the walls within 24 hours, the amount of $\mathrm{CO}_{2}$ in the drum was still increasing. The pair of experiments in Table 2 show that, although cellular metabolism on the wall did, indeed, occur, it did not account for the metabolic ${ }^{14} \mathrm{CO}_{2}$ evolved when SM and glucose were simultaneously aerosolized. In this experiment, one drum was first preconditioned by aerosolizing with labeled glucose alone and allowing all the glucose to fall out to the walls of the drum during a $72-\mathrm{hr}$ period. The drum was subsequently airwashed and then filled with airborne SM. Any resulting ${ }^{14} \mathrm{CO}_{2}$ in the drum would then represent metabolism on the walls ( $p$ lus any bleeding effects). These results are compared to a paralle1 drum experiment in which both SM and glucose were aerosolized simultaneously. The results of this experiment (Table 2) show that metabolism on the walls is not a significant contributor of $\mathrm{CO}_{2}$ until late in the time-course of the reaction. The $\mathrm{CO}_{2}$ formed soon after aerosolization of both SM and glucose must, then, be attributable to metabolism in the aerosol state.

An experiment (Table 3) was conducted in an effort to eliminate the effects of metabolism on the walls. SM and glucose were simultaneously aerosolized into each of two drums, one of which was coated with a $0.2 \mathrm{~N} \mathrm{Na}_{2} \mathrm{CO}_{3}$ solution to trap any ${ }^{14} \mathrm{CO}_{2}$ formed by metabolism on
the walls. Initial values of $\mathrm{CO}_{2}$ were similar in both drums. However, as shown, $\mathrm{CO}_{2}$ gradually increased in the absence of carbonate, whereas, in the presence of carbonate, $\mathrm{CO}_{2}$ remained constant or increased only slightly after the initial evolution. These results suggest that metabolism in air occurs soon after contact of the cell with the glucose particle and that further increases in $\mathrm{CO}_{2}$ contain a partial contribution of metabolism from cells on the walls. The magnitude of the wal1-effect seen in Table 3 is in general agreement with the results shown in Table 2 . The apparent magnitude of the $\mathrm{CO}_{2}$ increase (Table 3) is undoubtedly lower than the actual increase because of the known "gettering" effect of $\mathrm{Na}_{2} \mathrm{CO}_{3}$. 
2nd Quarterly Report, 1973-74

NASA Contract W13450

Task No. 193-58-62-13-10

As an additional indication of microbial metabolic activity in the air, we collected samples for 1 minute on $0.45 \mathrm{~km}$ membrane filters at flow rates of 5 liters of air/min. Filters were then rinsed 5 times with $2.0 \mathrm{ml}$ quantities of unlabeled $0.5 \%$ glucose and the filters counted for ${ }^{14} \mathrm{C}$ retention. Corrections were made for small amounts of glucose which tends to be retained on the filter even without cells. The remaining counts are referred to as insolubłe, particulate label (IPL), and presumably represent an estimate of the amount of incorporated glucose not yet metabolized to $\mathrm{CO}_{2}$. Although the dynamics of the IPL are complex, as is $\mathrm{CO}_{2}$ evolution, in all tests the IPL first increased, then decreased to background levels during the first 2 to $5 \mathrm{hr}$ period of aerosol life. In one experiment (Table 2), the IPL obtained with glucose plus SM appears to be the same as glucose alone (Table 1). However, there was a gross difference in physical fallout between the two experiments. When corrections are made accordingly, the IPI with glucose plus SM is significantly greater than that with glucose alone.

Together, these experiments indicate that metabolism can and does occur in the aerosol state. Under experimental conditions, metabo1 ism starts soon after initial interaction between glucose and bacterial cells. The fact that $\mathrm{CO}_{2}$ evolution from the airborne cells did not continue for an extended time after interaction with substrate may reflect total utilization of all glucose available to the bacterial cells, as the decline of IPL indicates. After the initial aerosolization, which optimizes coagulation, little additional coagulation occurs between SM and glucose in the airborne state within the drum. Alternatively, the outcome is similar to results of experiments conducted at Biospherics (10) in which $14 \mathrm{C}$-labeled substrates were added to coliform organisms. An initial burst of $14 \mathrm{CO}_{2}$ evolution was followed by a slower but continual rate of ${ }^{14} \mathrm{CO}_{2}$ release. Since coliform organisms were in continual contact with $14 \mathrm{C}-1$ abeled substrates, this kinetic phenomenon could not reflect lack of substrate availability. The rate of ${ }^{14} \mathrm{CO}_{2}$ evolution in the "Biospherics" studies increased again as growth and reproduction of the microorganisms began to occur.

At present, we have no evidence that growth and/or reproduction are occurring within the drum. It is possible that the kinetics observed for airborne metabolism may, therefore, reflect the "early burst" phenomenon and that, if the aerosol were maintained over longer periods, until growth and reproduction could occur, the metabolic rate would be resumed. Thus, whether or not the kinetics of airborne metabolism in these experiments represent a substrate-limited situation or reflect lack of growth is an issue to be resolved by further experimentation. 
2nd Quarterly Report, 1973-74

NASA Contract W1 3450

Task No. 193-58-62-13-10

\section{ACKNOWLEDGEMENTS}

Work supported in part by NASA, (Office of Planetary Quarantine) Contract $W-13,450$ and in part by the Office of Naval Research. We acknowledge the excellent assistance of Bruce Conner, A1 Boyd and Steve Dunn.

\section{REFERENCES}

1. D. Neil. The Planet Jupiter, NASA SP-8069 (1971).

2. J. E. Benbough and P. Hambleton in Airborne Transmission and Air Infection, J. F. Hers and K. C. Winkler, Eds. (Oosthoek Publishing Co., Utrecht, The Netherlands, (1973) p. 135; R. L. Dimmick, ibid. P. 100; P. Hambleton, J. Gen. Microbiol. 69:81 (1971);

C. S. Cox and F. Baldwin, ibid, 44:15 (1966).

3. M. T. Hatch and H. Wolochow in Intro. to Expt1. Aerobiol., R. L. Dimmick and A. Akers, Eds. (J. Wiley, N. Y. 1969) P. 267.

4. P. C. Parker, Nat. History, Oct. 55 (1970).

5. F. Woeller and C. Ponnamperuma., ICARUS, 10:386 (1969).

6. G. V. Levin, A. H. Heim, J. R. Clendenning and M. F. Thompson, Science, 138:114 (1962); G. V. Levin, ICARUS, 16:153 (1972).

7. K. B. DeOme et a1., Am. J. Hyg. 40:239 (1944).

8. L. J. Goldberg et a1., ibid, 68:85 (1958).

9. P. S. Brachman et a1., Science, 144:1295 (1964).

10. G. V. Levin, V. R. Harrison and W. C. Hess, J. Am. Water Works Assoc., 49:1069 (1957); G. V. Levin, Adv. App1. Microbio1. $\underline{5}$ : $95(1963)$. 
Table 1. Test of metabollsm; glucose agalnst glucose plus bacteria.

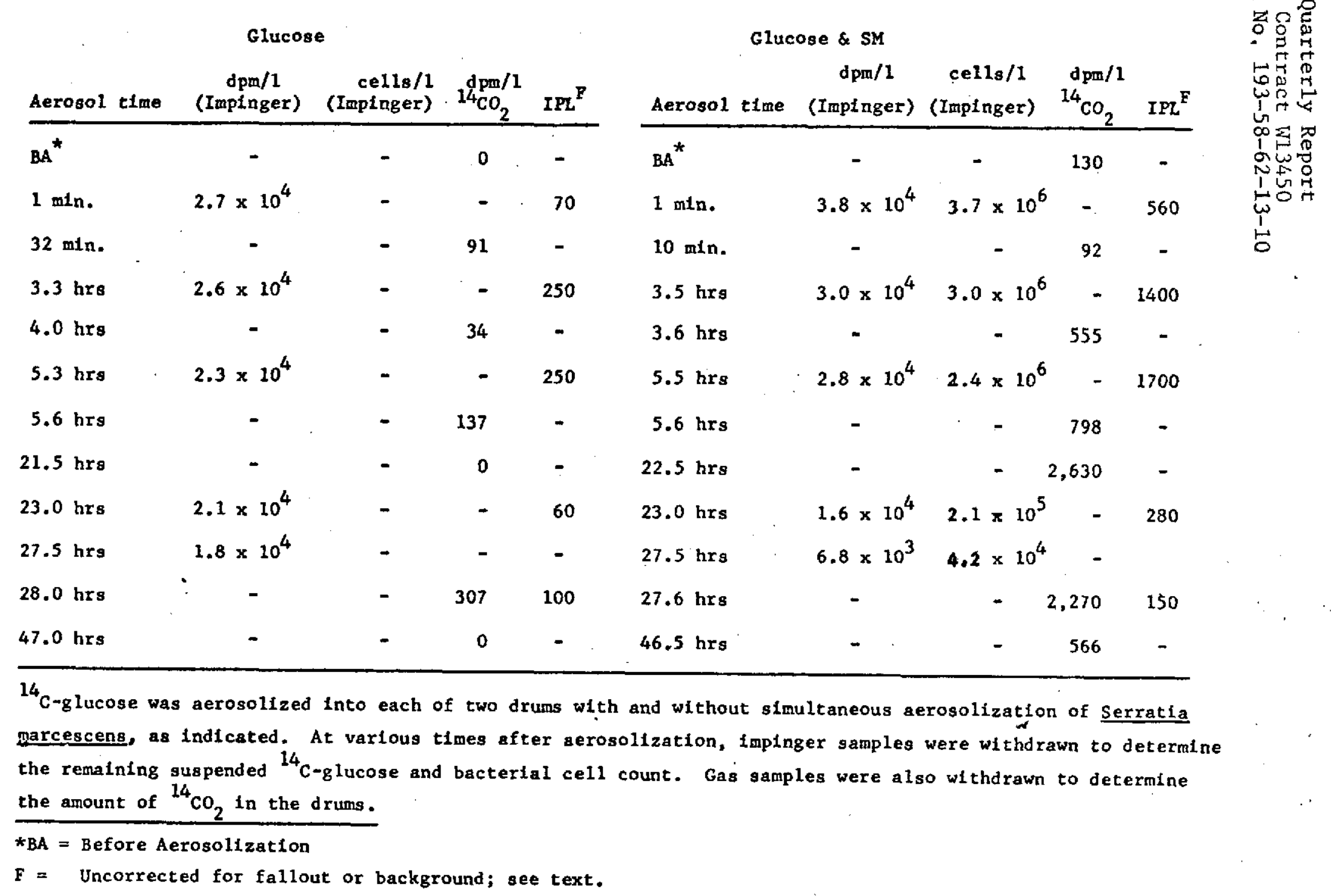




\section{Page intentionally left blank}


Table 3. Test of metabolism; with and without $\mathrm{CO}_{2}$ adsorbant.

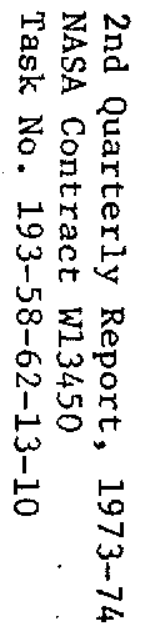

\begin{tabular}{|c|c|c|c|c|c|c|c|c|c|c|}
\hline \multicolumn{5}{|c|}{ Glucose \& SM $\left(-\mathrm{Na}_{2} \mathrm{CO}_{3}\right)$} & \multicolumn{6}{|c|}{ Glucose \& SM $\left(+\mathrm{Na}_{2} \mathrm{CO}_{3}\right)$} \\
\hline Aerosol & time & $\begin{array}{c}\mathrm{dpm} / 1 \\
\text { (Impinger) }\end{array}$ & $\begin{array}{l}\text { cells/l } \\
\text { (Impinger) }\end{array}$ & $\begin{array}{l}\mathrm{dpm} / \mathrm{p} \\
14 \mathrm{CO}_{2}\end{array}$ & IPL ${ }^{\mathrm{F}}$ & Aerosol time & $\begin{array}{l}\text { dpm/1 } \\
\text { (Impinger) }\end{array}$ & $\begin{array}{l}\text { cells/1 } \\
\text { (Impinger) }\end{array}$ & $\begin{array}{l}\mathrm{dpm} / 1 \\
14 \mathrm{CO}_{2}\end{array}$ & $I P L^{\mathbf{F}}$ \\
\hline $\mathrm{BA} *$ & & - & - & 0 & - & $B A^{*}$ & - & - & 0 & - \\
\hline $1 \mathrm{mLn}$ & & $3.6 \times 10^{4}$ & $4.5 \times 10^{6}$ & - & - & $1 \mathrm{~min}$ & $3.6 \times 10^{4}$ & $5.9 \times 10^{6}$ & - & - \\
\hline $4 \mathrm{~min}$ & & - & - & - & 742 & $3 \mathrm{mfn}$ & - & - & - & 354 \\
\hline $20 \mathrm{~min}$ & & - & - & 349 & - & $8 \min$ & - & - & 289 & - \\
\hline $3 \mathrm{hrs}$ & . & $2.2 \times 10^{4}$ & $2.2 \times 10^{6}$ & - & 578 & $3.2 \mathrm{hrs}$ & $2.1 \times 10^{4}$ & $1.9 \times 10^{6}$ & - & 402 \\
\hline $3.5 \mathrm{hrs}$ & & - & - & 729 & & $3.3 \mathrm{hrs}$ & - & - & 462 & - \\
\hline $4.7 \mathrm{hrs}$ & & $1.5 \times 10^{4}$ & $1.4 \times 10^{6}$ & - & 119 & $5.2 \mathrm{hrs}$ & $1.6 \times 10^{4}$ & $1.2 \times 10^{6}$ & - & 362 \\
\hline $5.6 \mathrm{hrs}$ & & - & - & 511 & - & $5.5 \mathrm{hrg}$ & - & - & 332 & - \\
\hline $23.5 \mathrm{hrs}$ & . & - & - & 1,448 & - & $23.4 \mathrm{hrs}$ & - & - & 318 & - \\
\hline $24.6 \mathrm{hrs}$ & & $5.4 \times 10^{3}$ & $2.2 \times 10^{5}$ & - & 78 & $24.7 \mathrm{hrs}$ & $5.0 \times 10^{3}$ & $2.4 \times 10^{5}$ & - & 82 \\
\hline $28.0 \mathrm{hrs}$ & & $4 \times 10^{3}$ & $1.4 \times 10^{5}$ & - & 44 & $28.5 \mathrm{hrs}$ & $3.7 \times 10^{3}$ & $1.2 \times 10^{5}$ & - & - \\
\hline $28.6 \mathrm{hrs}$ & & - & - & 1,218 & - & $28.6 \mathrm{hrs}$ & - & - & 374 & 28 \\
\hline $48.7 \mathrm{hrs}$ & & $1.8 \times 10^{3}$ & $3 \times 10^{4}$ & - & - & $49.2 \mathrm{hrs}$ & $2.0 \times 10^{2}$ & - & $\sim$ & - \\
\hline $49.5 \mathrm{hrs}$ & & - & - & 1,348 & - & $51.5 \mathrm{hrs}$ & - & - & 419 & - \\
\hline
\end{tabular}

${ }^{14} \mathrm{C}-\mathrm{g}$ lucose and Serratia marcescens (SM) were simultaneously aerosolized into each of two drums, one of which had previously been lined with $\mathrm{Na}_{2} \mathrm{CO}_{3}$, as indicated. At various times after aerosolization, impinger samples were withdrawn to determine the remaining suspended ${ }^{14} \mathrm{C}-\mathrm{glucose}$ and bacterial cell count. Gas samples were also wtthdrawn to determine the amount of ${ }^{14} \mathrm{CO}_{2}$ in the drums.

$\star \mathrm{BA}=$ Before Aerosolization

$F$ = uncorrected for fallout and background, see text. 